\title{
Protective effect of extract of Cordyceps sinensis in middle cerebral artery occlusion-induced focal cerebral ischemia in rats
}

\author{
Zhenquan Liu', Pengtao Li ${ }^{1}$, Dan Zhao ${ }^{1}$, Huiling Tang ${ }^{1}$, Jianyou Guo ${ }^{2 *}$
}

\begin{abstract}
Background: Ischemic hypoxic brain injury often causes irreversible brain damage. The lack of effective and widely applicable pharmacological treatments for ischemic stroke patients may explain a growing interest in traditional medicines. From the point of view of "self-medication" or "preventive medicine," Cordyceps sinensis was used in the prevention of cerebral ischemia in this paper.

Methods: The right middle cerebral artery occlusion model was used in the study. The effects of Cordyceps sinensis (Caterpillar fungus) extract on mortality rate, neurobehavior, grip strength, lactate dehydrogenase, glutathione content, Lipid Peroxidation, glutathione peroxidase activity, glutathione reductase activity, catalase activity, $\mathrm{Na}^{+} \mathrm{K}^{+} \mathrm{ATPase}$ activity and glutathione $\mathrm{S}$ transferase activity in a rat model were studied respectively.

Results: Cordyceps sinensis extract significantly improved the outcome in rats after cerebral ischemia and reperfusion in terms of neurobehavioral function. At the same time, supplementation of Cordyceps sinensis extract significantly boosted the defense mechanism against cerebral ischemia by increasing antioxidants activity related to lesion pathogenesis. Restoration of the antioxidant homeostasis in the brain after reperfusion may have helped the brain recover from ischemic injury.

Conclusions: These experimental results suggest that complement Cordyceps sinensis extract is protective after cerebral ischemia in specific way. The administration of Cordyceps sinensis extract significantly reduced focal cerebral ischemic/reperfusion injury. The defense mechanism against cerebral ischemia was by increasing antioxidants activity related to lesion pathogenesis.
\end{abstract}

\section{Background}

Ischemic hypoxic brain injury often causes irreversible brain damage. The cascade of events leading to neuronal injury and death in ischemia includes the release of cytokines and free radicals, and induction of inflammation, apoptosis, and excitotoxicity [1]. Reperfusion of ischemic areas could exacerbate ischemic brain damage through the generation of reactive oxygen species. The lack of effective and widely applicable pharmacological treatments for ischemic stroke patients may explain a growing interest in traditional medicines. Recently, from the point of view of "self-medication" or "preventive medicine," several dietary supplements are used in the

\footnotetext{
* Correspondence: guojianyou@126.com

${ }^{2}$ Key Laboratory of Mental Health, Institute of Psychology, Chinese Academy of Sciences, Beijing 100101, P.R China

Full list of author information is available at the end of the article
}

prevention of life-style related diseases including cerebral ischemia.

Mushrooms and primarily basidiomycetous fungi are popular and valuable foods that are low in calories and high in minerals, essential amino acids, vitamins, and fibers [2]. Some of them produce substances with potential medical effects, and are called medicinal mushrooms [3]. Cordyceps sinensis (Caterpillar fungus) (CS) has been used as a tonic for longevity, endurance, and vitality for thousands of years by the Chinese [4]. Many studies have shown that Cordyceps sinensis (CS) modulates immune responses [5-7], inhibits tumor cell proliferation $[8,9]$, enhances hepatic function [10], regulates insulin sensitivity [11], decreases plasma cholesterol levels [12], and has hypotensive and vasorelaxant activity [13]. In particular, CS modulates steroidogenesis. Huang reported that CS induced $17 \beta$-estradiol production [14]. 
There is strong evidence that chronic $17 \beta$-estradiol treatment has both potent and long-lasting effects on improved pathophysiological outcome after brain ischemia in experimental animal models $[15,16]$. Clinical studies have demonstrated that estrogens enhance mood and cognition and delay cognitive decline $[17,18]$. Thus, we hypothesize that Cordyceps sinensis possess protective effect of against ischemia-induced brain infarction by modulating $17 \beta$-estradiol production. The present study investigated the effects of Cordyceps sinensis on mortality rate, neurobehavior, grip strength, lactate dehydrogenase, glutathione content, Lipid Peroxidation, glutathione peroxidase activity, glutathione reductase activity, catalase activity, $\mathrm{Na}^{+} \mathrm{K}^{+}$ATPase activity and glutathione $S$ transferase activity in a rat model. These data may help in the development of effective and widely applicable pharmacological treatments for ischemic stroke patients with traditional medicines.

\section{Materials and methods \\ Animals}

Healthy male adult wistar rats (2 months old and weighing $225 \pm 25 \mathrm{~g}$ ) were used in the study. This study was performed in accordance with the Guide for the Care and Use of Laboratory Animals. Care was taken to minimize discomfort, distress, and pain to the animals.

\section{Chemicals}

\section{Cordyceps sinensis extract (CSE) preparation}

The seed of Cordyceps sinensis was purchased from the Agricultural Culture Collection of China. Five to six pieces of the mycelia of Cordyceps sinensis were transferred from a slant into $500 \mathrm{~mL}$ Erlenmeyer flasks containing $300 \mathrm{~mL}$ of fermented culture medium $(20 \%$ potato extract liquid $+2.0 \%$ dextrose $+0.1 \% \mathrm{KH}_{2} \mathrm{PO}_{4}+$ $0.05 \% \mathrm{MgSO}_{4}$ ). The culture was incubated at $27^{\circ} \mathrm{C}$ on a rotary shaker at $180 \mathrm{rmp}$ for 7 days [19,20].

Preparation of the CSE was as follows: $30 \mathrm{~g}$ of cultured Cordyceps sinensis mycelium powder was extracted with $240 \mathrm{ml}$ of water in a water bath of $100^{\circ} \mathrm{C}$ for $3 \mathrm{~h}$ with reflux. Eighty milliliters of the water extract was then lyophilized to yield $2.9 \mathrm{~g}$ of the dry powder. The rest of the water extract $(160 \mathrm{ml})$ was mixed with $160 \mathrm{ml}$ of absolute ethanol for extraction. This $50 \%$ alcoholic fraction was dried to yield $3.7 \mathrm{~g}$ of the dry powder. The combination of both aqueous and alcohol extracts was then used in the present study.

\section{Experimental design}

The animals were separated into three groups of eight rats each. The first group served as sham (SHAM). The second group was the ischemic group (MCAO). Group I and group II were treated orally by distilled water for 30 days respectively. Group III (CSE-4), Group IV (CSE-8)

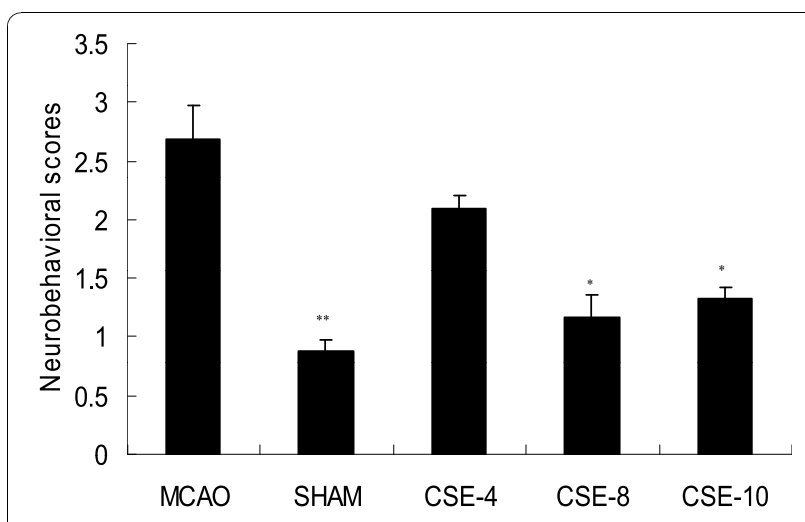

Figure 1 Effect of CSE on the Development of Behavioral Abnormalities after middle cerebral artery occlusion. Values are shown as means \pm SEM. ${ }^{*} p<0.05$ vs. MCAO group, ${ }^{* *} p<0.01$ vs. MCAO group. $\left(F_{\text {SHAM }}=17.642, \mathrm{df}_{\text {SHAM }}=11, \mathrm{p}_{\mathrm{SHAM}}=0.001, \mathrm{~F}_{\mathrm{CSE}-4}=\right.$ 2.252, df CSE-4 $_{1}=11, \mathrm{P}_{\text {CSE- }-4}=0.162, \mathrm{~F}_{\text {CSE- } 8}=16.396, \mathrm{df}$ CSE-8 $=11$, $\left.p_{\text {CSE- } 8}=0.01, F_{C S E-10}=22.738, d_{\text {SHAM }}=11, p_{\text {SHAM }}=0.02\right)$.

and Group V (CSE-10) were treated orally by CSE (4, 8 and $10 \mathrm{mg} / \mathrm{kg} /$ day respectively) for 30 days followed by MCAO induced cerebral ischemia.

The right middle cerebral artery occlusion (MCAO) was performed using an intraluminal filament model and the method described by Longa et al. [21]. In brief, the rats were anesthetized with chloral hydrate $(400 \mathrm{mg} /$ $\mathrm{kg}$, i.p.), a 4-0 nylon monofilament with a blunt end was introduced into the external carotid artery (ECA) and advanced into the middle cerebral artery via the internal carotid artery (ICA) (17-20 mm), until a slight resistance was felt. Successful occlusion was confirmed by an $87-90 \%$ reduction in cerebral blood flow (CBF), as measured by laser-Doppler flowmetry [22].

Two hours after the induction of ischemia, the filament was slowly withdrawn and the animals were returned to their cages for a period of 22 hours of reperfusion. Throughout the procedure, the body temperature was maintained at $37^{\circ} \mathrm{C}$, with a thermostatically controlled infrared lamp. In sham rats, the ECA was surgically prepared for the insertion of the filament, but the filament was not inserted. The final number of rats was as follows: SHAM group $\mathrm{n}=8$; MCAO group

Table 1 Effect of CSE on basal grip strength

\begin{tabular}{lllll}
\hline Different groups & $\begin{array}{l}\text { Grip strength } \\
\text { (Kg Units) }\end{array}$ & F-values & df-values & p-values \\
\hline MCAO group & $0.598 \pm 0.004^{\mathrm{b}}$ & & & \\
SHAM group & $0.963 \pm 0.006^{\mathrm{a}}$ & 0.158 & 11 & 0.001 \\
CSE-4 group & $0.663 \pm 0.022^{\mathrm{b}}$ & 0.158 & 11 & 0.445 \\
CSE-8 group & $0.978 \pm 0.005^{\mathrm{a}}$ & 0.146 & 11 & 0.001 \\
CSE-10 group & $0.890 \pm 0.013^{\mathrm{a}}$ & 2.964 & 11 & 0.005 \\
\hline
\end{tabular}

Values are shown as means \pm SEM. The different letters in the same column indicate a statistical difference ( $p<0.01$ vs. MCAO group). 
Table 2 Effect of CSE on serum LDH levels

\begin{tabular}{lllll}
\hline Different groups & LDH (IU/L) & F-values & df-values & p-values \\
\hline MCAO group & $170.201 \pm 3.741$ & & & \\
SHAM group & $86.322 \pm 2.663^{* * *}$ & 6.556 & 5.183 & 0.000 \\
CSE-4 group & $156.601 \pm 2.221$ & 7.199 & 11 & 0.118 \\
CSE-8 group & $106.632 \pm 3.111^{* *}$ & 7.497 & 5.063 & 0.001 \\
CSE-10 group & $131.232 \pm 2.101^{* *}$ & 0.426 & 11 & 0.005 \\
\hline
\end{tabular}

Values are shown as means \pm SEM. ${ }^{* *} p<0.01$ vs. MCAO group, ${ }^{* * *} p<0.001$ vs. MCAO group

$\mathrm{n}=6$; CSE-4 group $\mathrm{n}=6$; CSE- 8 group $\mathrm{n}=7$ and CSE10 group $\mathrm{n}=8$.

\section{Neurobehavioral test}

The sensorimotor integrity was conducted to assess the neurobehavior at $24 \mathrm{~h}$ after MCAO in rats [23]. Five categories of motor neurological findings were scored: 0 , no observable deficit; 1 , forelimb flexion; 2 , forelimb flexion and decreased resistance to lateral push; 3 , forelimb flexion, decreased resistance to lateral push and unilateral circling; 4, forelimb flexion, unable or difficult to ambulate. Animals that showed the features of the higher scores also showed all the features of the lower grades.

\section{Grip strength study}

Grip strength in all the animals was measured for evaluation of neuromuscular strength, as described by Ali et al. [24]. The neuromuscular strength tests were carried out between 9:00 a.m. to 4:00 p.m. under standard laboratory conditions.

\section{Tissue preparation}

After grip strength measurement, blood samples were drawn from the tail vein from all the groups and serum was separated for biochemical estimations. Thereafter, the animals were sacrificed immediately and their brains were taken out to dissect the hippocampus (HIP). Post-mitochondrial supernatant (PMS) obtained from $10 \%$ homogenate of tissue was used for the estimation of various parameters related with oxidative stress.

\section{Biochemical estimations}

In serum, lactate dehydrogenase (LDH) was estimated using a method described by Lum et al [25]. The PMS and HIP were used for the assay of glutathione (GSH) content, Lipid peroxidation (LPO), glutathione peroxidase (GPx) activity, glutathione reductase (GR) activity, catalase (CAT) activity, $\mathrm{Na}^{+} \mathrm{K}^{+} \mathrm{ATPase}$ activity and glutathione $\mathrm{S}$ transferase (GST) activity [26-31].

\section{Statistical analysis}

The data are expressed as mean \pm SEM. Statistical differences between means were determined by one-way analysis of variance (ANOVA), followed by Dunnett $t$ test. The values of $P<0.05$ were considered as significant.

\section{Results and discussion}

In this study, the cerebroprotective effect of Cordyceps sinensis extract on ischemic neuronal damage was clearly demonstrated using focal ischemia model rats.

The behavioral tasks adopted in this study were designed to assess impairments consistent with the known functional architecture of the rat brain.

Twenty-four hours after MCAO in rats, neurological deficit scores were significantly reduced in CSE-8 -treated rats and CSE-10 -treated rats. The neurobehavior for the SHAM group was $0.9(0.6-1.1)$, the MCAO group was 3.7 (2.6-5.3), the CSE-4 group was 2.2 (1.8$4.1)$, the CSE- 8 group was $1.2(0.8-4.1)$ and the CSE-10 group was $1.5(1.0-4.1)$. It is clear that the behavioral abnormality was significantly developed in the MCAO group as compared with the sham (Figure 1). In contrast, the CSE-8 group and CSE-10 significantly suppressed the development of behavioral abnormality as compared with the MCAO group (Figure 1).

The grip strength in the SHAM group was found to be $0.963 \pm 0.006 \mathrm{~kg}$ units. A significant decrease in the grip strength was observed in the MCAO group, as compared to the sham rats $(P<0.01)$. CSE- 8 and CSE10 treated rats showed a significant increase in grip strength, as compared to the MCAO group $(P<0.01)$ (Table 1).

Table 3 Effect of CSE on Hippocampus GSH

\begin{tabular}{lllll}
\hline Different groups & Hippocampus GSH (nmol GSH/mg protein) & F-values & df-values & p-values \\
\hline MCAO group & $0.763 \pm 0.025$ & & & 0.285 \\
SHAM group & $2.298 \pm 0.013^{* *}$ & 7.992 & 11 & 0.009 \\
CSE-4 group & $1.015 \pm 0.015$ & 1.863 & 6.379 & 0.379 \\
CSE-8 group & $2.465 \pm 0.055^{* *}$ & 6.537 & 0.008 \\
CSE-10 group & $1.233 \pm 0.022^{*}$ & 2.964 & 11 & 0.025 \\
\hline
\end{tabular}

Values are shown as means \pm SEM. ${ }^{*} p<0.05$ vs. MCAO group, ${ }^{* *} p<0.01$ vs. MCAO group 
Table 4 Effect of CSE on Cerebral cortex GSH

\begin{tabular}{lllll}
\hline Different groups & Cerebral cortex GSH $(\mathbf{n m o l ~ G S H} / \mathbf{m g}$ protein) & F-values & df-values & p-values \\
\hline MCAO group & $1.012 \pm 0.010$ & & & 0.017 \\
SHAM group & $1.803 \pm 0.026^{*}$ & 4.193 & 11 & 0.336 \\
CSE-4 group & $1.095 \pm 0.021$ & 4.043 & 11 & 0.026 \\
CSE-8 group & $1.495 \pm 0.053^{*}$ & 3.306 & 11 & 0.427 \\
CSE-10 group & $1.295 \pm 0.011^{*}$ & 3.418 & 11 & \\
\hline
\end{tabular}

Values are shown as means \pm SEM. ${ }^{*} p<0.05$ vs. MCAO group.

Increasing evidence has indicated that ischemia/reperfusion occurs due to oxidative stress that may potentiate ischemic injury [32]. Lactate dehydrogenase was measured to evaluate the role of antioxidative stress in the protection of CSE. The serum LDH levels in SHAM group were found to be $86.322 \pm 2.663 \mathrm{IU} / \mathrm{L}$. A significant increase in the activity of LDH in serum was observed in MCAO group, as compared to the SHAM group; whereas, CSE-8 and CSE-10 treatment significantly resulted in decreased serum LDH levels when compared with MCAO group rats (Table 2).

Reduced glutathione (GSH) is one of the primary endogenous antioxidant defense systems in the brain, which removes hydrogen peroxide and lipid peroxides. Decline in GSH levels could either increase or reflect oxidative status [33,34]. Concentrations of GSH were lower in MCAO group than those in SHAM group (Table 3 and Table 4). CSE-8 produced the increase in the level of GSH significantly. The same results did occur in the CSE-10 group.

It can be attributed to several factors such as cleavage GSH to cysteine, decrease in the synthesis of GSH and the formation of mixed disulfides, causing their cellular stores to be depleted [35].

The large numbers of polyunsaturated fatty acids make cell membranes particularly vulnerable to lipid peroxidation. The oxidation of polyunsaturated fatty acids alters the structure of the membrane with resultant changes in fluidity and permeability. Lipid peroxidation can also inhibit the function of membrane bound receptors and enzymes [36]. The level of LPO content adds to the proof of the increased peroxidative damage during cerebral ischemia. A significant increase in the

Table 5 Effect of CSE on LPO level

\begin{tabular}{lllll}
\hline $\begin{array}{l}\text { Different } \\
\text { groups }\end{array}$ & $\begin{array}{l}\text { nmol LPO/g } \\
\text { protein }\end{array}$ & F-values & df-values & p-values \\
\hline MCAO group & $20.21 \pm 1.41$ & & & \\
SHAM group & $13.23 \pm 0.66^{* *}$ & 5.254 & 6.996 & 0.003 \\
CSE-4 group & $20.01 \pm 0.21$ & 19.460 & 5.010 & 0.846 \\
CSE-8 group & $15.32 \pm 0.11^{*}$ & 1.304 & 10 & 0.043 \\
CSE-10 group & $15.22 \pm 0.21^{*}$ & 1.305 & 10 & 0.042 \\
\hline
\end{tabular}

Values are shown as means \pm SEM. ${ }^{*} p<0.05$ vs. MCAO group, ${ }^{* *} p<0.01$ vs. MCAO group. content of LPO was observed in the MCAO group when compared with the SHAM group. In the CSE-8 and CSE-10 group, a significant decrease was seen in the level of LPO when compared with the MCAO group (Table 5).

It has been proposed that antioxidant changes reflect an altered redox balance in several pathological states. The antioxidants would be consumed in the reaction with free radicals. Therefore, the measurement of endogenous antioxidants enzymes i.e. GPx, GR, CAT and GST as well as $\mathrm{Na}^{+} \mathrm{K}^{+}$ATPase has been performed to estimate the amount of oxidative stress. Activities of various antioxidant enzymes and $\mathrm{Na}^{+} \mathrm{K}^{+} \mathrm{ATPase}$ of different groups have been listed in Table 6 , Table 7 , Table 8, Table 9 and Table 10. The activity of endogenous antioxidant enzymes was decreased significantly in the MCAO group, as compared to the sham group, whereas in the CSE-8 group, CSE-treatment showed a significant restoration in the level of various enzymes as compared with MCAO group. The same results did occur in the CSE-10 group.

A great deal of effort has been directed toward searching for a new drug that can be used for protection of cerebral ischemia-reperfusion injury. From the point of view of "self-medication" or "preventive medicine," Cordyceps sinensis was used in the prevention of cerebral ischemia in this paper. Although Cordyceps sinensis is extensively used in Chinese medicine, it lacks scientific grounds for its efficacy and to the best of our knowledge this is the first study to report its possible protective mechanisms against cerebral ischemic damage.

Here we showed that the Cordyceps sinensis extract significantly improved the outcome in rats after cerebral ischemia and reperfusion in terms of neurobehavioral

\section{Table 6 Effect of CSE on the activity of GPx}

\begin{tabular}{lllll}
\hline Different groups & GPx & F-values & df-values & p-values \\
\hline MCAO & $8.01 \pm 0.42$ & & & \\
\hline SHAM & $15.98 \pm 1.23^{* *}$ & 0.714 & 11 & 0.001 \\
CSE-4 & $9.10 \pm 1.02$ & 0.911 & 11 & 0.306 \\
CSE-8 & $12.16 \pm 1.32^{* *}$ & 3.557 & 11 & 0.006 \\
CSE-10 & $10.10 \pm 1.11^{*}$ & 0.052 & 11 & 0.04 \\
\hline
\end{tabular}

Values are shown as means \pm SEM. ${ }^{*} p<0.05$ vs. MCAO group, ${ }^{* *} p<0.01$ vs. MCAO group. 
Table 7 Effect of CSE on the activity of GR

\begin{tabular}{lllll}
\hline Different groups & GR & F-values & df-values & p-values \\
\hline MCAO & $20.88 \pm 2.11$ & & & \\
\hline SHAM & $35.55 \pm 2.51^{* *}$ & 0.953 & 11 & 0.006 \\
CSE-4 & $21.01 \pm 2.02$ & 0.03 & 11 & 0.954 \\
CSE-8 & $29.01 \pm 2.22^{*}$ & 4.394 & 11 & 0.028 \\
CSE-10 & $25.00 \pm 2.31^{*}$ & 4.929 & 11 & 0.048 \\
\hline
\end{tabular}

Values are shown as means \pm SEM. ${ }^{*} p<0.05$ vs. MCAO group, ${ }^{* *} p<0.01$ vs. MCAO group.

Table 8 Effect of CSE on the activity of GST

\begin{tabular}{lllll}
\hline Different groups & GST & F-values & df-values & p-values \\
\hline MCAO & $10.07 \pm 1.11$ & & & \\
\hline SHAM & $15.00 \pm 1.22^{* *}$ & 16.088 & 13 & 0.002 \\
CSE-4 & $10.60 \pm 0.97$ & 9.946 & 10 & 0.680 \\
CSE-8 & $13.60 \pm 0.98^{* *}$ & 19.214 & 11 & 0.008 \\
CSE-10 & $12.60 \pm 0.88^{*}$ & 20.293 & 12 & 0.029
\end{tabular}

Values are shown as means \pm SEM. ${ }^{*} p<0.05$ vs. MCAO group, ${ }^{* *} p<0.01$ vs. MCAO group.

Table 9 Effect of CSE on the activity of CAT

\begin{tabular}{lllll}
\hline Different groups & CAT & F-values & df-values & p-values \\
\hline MCAO & $4.22 \pm 0.13$ & & & \\
\hline SHAM & $6.11 \pm 0.33^{*}$ & 7.196 & 12 & 0.010 \\
CSE-4 & $4.78 \pm 0.24$ & 3.917 & 10 & 0.076 \\
CSE-8 & $5.78 \pm 0.23^{*}$ & 6.977 & 11 & 0.02 \\
CSE-10 & $5.70 \pm 0.30^{*}$ & 6.858 & 11 & 0.024
\end{tabular}

Values are shown as means \pm SEM. ${ }^{*} p<0.05$ vs. MCAO group.

\section{Table 10 Effect of CSE on the activity of $\mathrm{Na}^{+} \mathrm{K}^{+}$ATPase}

\begin{tabular}{lllll}
\hline Different groups & $\mathbf{N a}^{+} \boldsymbol{K}^{+} \mathbf{A T P a s e}$ & $\mathbf{F}$-values & $\mathbf{d f}$-values & $\boldsymbol{p}$-values \\
\hline MCAO & $2.00 \pm 0.13$ & & & \\
SHAM & $4.52 \pm 0.32^{* *}$ & 16.967 & 11 & 0.002 \\
CSE-4 & $2.11 \pm 0.10$ & 0.175 & 11 & 0.684 \\
CSE-8 & $3.11 \pm 0.11^{*}$ & 17.788 & 11 & 0.001 \\
CSE-10 & $4.13 \pm 0.22^{*}$ & 16.302 & 11 & 0.002 \\
\hline
\end{tabular}

Values are shown as means \pm SEM. ${ }^{*} p<0.05$ vs. MCAO group, ${ }^{* *} p<0.01$ vs. MCAO group.

function. At the same time, supplementation of Cordyceps sinensis extract significantly boosted the defense mechanism against cerebral ischemia by increasing antioxidants activity related to lesion pathogenesis. Restoration of the antioxidant homeostasis in the brain after reperfusion may have helped the brain recover from ischemic injury.

\section{Conclusions}

These experimental results suggest that complement Cordyceps sinensis extract is protective after cerebral ischemia in specific way. The administration of CSE significantly reduced focal cerebral ischemic/reperfusion injury. The defense mechanism against cerebral ischemia was by increasing antioxidants activity related to lesion pathogenesis.

\section{Acknowledgements}

This work was supported by the Key New Drugs Innovation project from Ministry of Science and Technology (2009ZX09502-017), the project from Key Laboratory of Mental Health, Chinese Academy of Sciences, Young Scientist project from IPCAS (08CX043004), NNSF grant (30800301), the Knowledge Innovation Program of the Chinese Academy of Sciences (KSCX2-YW-R-254).

\section{Author details}

${ }^{1}$ School of Basic Medical Sciences, Beijing University of Chinese Medicine, Beijing 100029, P.R China. ${ }^{2}$ Key Laboratory of Mental Health, Institute of Psychology, Chinese Academy of Sciences, Beijing 100101, P.R China.

\section{Authors' contributions}

ZL conceived of the study, and participated in its design and coordination. PL participated in the operation of the study. DZ participated in the statistical analysis. HT carried out the preparation of CSE. JG drafted the manuscript. All authors read and approved the final manuscript.

\section{Competing interests}

The authors declare that they have no competing interests.

Received: 21 July 2010 Accepted: 19 October 2010

Published: 19 October 2010

\section{References}

1. Kuroda S, Siesjo BK: Reperfusion damage following focal ischemia: pathophysiology and therapeutic windows. Clin Neurosci 1997, 4:199-212.

2. Firenzuoli F, Gori L, Lombardo G: The Medicinal Mushroom Agaricus blazei Murrill: Review of Literature and Pharmaco-Toxicological Problems. Evid Based Complement Alternat Med 2008, 5(1):3-15.

3. Guo JY, Han CC, Liu YM: A Contemporary Treatment Approach to Both Diabetes and Depression by Cordyceps sinensis, Rich in Vanadium. Evid Based Complement Alternat Med 2010, 7:387-389.

4. Zhu JS, Halpern GM, Jones K: The scientific rediscovery of an ancient Chinese herbal medicine: Cordyceps sinensis. J Altern Complem Med 1998, 4:289-303.

5. Kuo YC, Tsai WJ, Shiao MS, Chen CF, Lin CY: Cordyceps sinensis as an immunomodulatory agent. Am J Chin Med 1996, 24:111-125.

6. Yang LY, Chen A, Kuo YC, Lin CY: Efficacy of a pure compound H1-A extracted from Cordyceps sinensis on autoimmune disease of MRL Ipr/ Ipr mice. J Lab Clin Med 1999, 134:492-500.

7. Kuo YC, Tsai WJ, Wang JY, Chang SC, Lin CY, Shiao MS: Regulation of bronchoalveolar lavage fluids cell function by the immunomodulatory agents from Cordyceps sinensis. Life Sci 2001, 68:1067-1082.

8. Kuo YC, Lin CY, Tsai WJ, Wu CL, Chen CF, Shiao MS: Growth inhibitors against tumor cells in Cordyceps sinensis other than cordycepin and polysaccharides. Cancer Invest 1994, 12:611-615.

9. Bok JW, Lermer L, Chilton J, Klingeman HG, Towers GH: Antitumor sterols from the mycelia of Cordyceps sinensis. Phytochemistry 1999, 51:891-898

10. Manabe N, Azuma Y, Sugimoto M, Uchio K, Miyamoto M, Taketomo N, Tsuchita H, Miyamoto H: Effects of the mycelial extract of cultured Cordyceps sinensis on in vivo hepatic energy metabolism and blood flow in dietary hypoferric anaemic mice. Br J Nutr 2000, 83:197-204.

11. Balon TW, Jasman AP, Zhu JS: A fermentation product of Cordyceps sinensis increases whole-body insulin sensitivity in rats. J Altern Complement Med 2002, 8:315-323.

12. Koh JH, Kim JM, Chang UJ, Suh HJ: Hypocholesterolemic effect of hotwater extract from mycelia of Cordyceps sinensis. Biol Pharm Bull 2003, 26:84-87.

13. Chiou WF, Chang PC, Chou CJ, Chen CF: Protein constituent contributes to the hypotensive and vasorelaxant activities of Cordyceps sinensis. Life Sci 2000, 66:1369-1376.

14. Huang BM, Hsiao KY, Chuang PC, Wu MH, Pan HA, Tsai SJ: Upregulation of steroidogenic enzymes and ovarian 17beta-estradiol in human 
granulosa-lutein cells by Cordyceps sinensis mycelium. Biol Reprod 2004, 70(5):1358-64.

15. Jover T, Tanaka H, Calderone A, Oguro K, Bennett MV, Etgen AM, Zukin RS Estrogen protects against global ischemia-induced neuronal death and prevents activation of apoptotic signaling cascades in the hippocampal CA1. J Neurosci 2002, 22:2115-2124.

16. McCullough LD, Hurn PD: Estrogen and ischemic neuroprotection: an integrated view. Trends Endocrinol Metab 2003, 14:228-235.

17. Kawas C, Resnick S, Morrison A, Brookmeyer R, Corrada M, Zonderman A, Bacal C, Lingle D, Metter E: A prospective study of estrogen replacementtherapy and the risk of developing Alzheimer's disease: the Baltimore longitudinal study of aging. Neurology 1997, 48:1517-1521.

18. Sherwin BB: Can estrogen keep you smart? Evidence from clinical studies. J Psychiatry Neurosci 1999, 24:315-321.

19. Chunchao H, Junhua Y, Yingzi W, Lingjun L: Hypoglycemic activity of fermented mushroom of Coprinus comatus rich in vanadium. $J$ Trace Elem Med Biol 2006, 20:191-196.

20. Han C, Liu T: A comparison of hypoglycemic activity of three species of basidiomycetes rich in vanadium. Biol Trace Elem Res 2009, 127(2):177-82.

21. Longa EZ, Weinstein PR, Carlson S, Cummins R: Reversible middle cerebral artery occlusion without craniectomy in rats. Stroke 1989, 20:84-91.

22. Shah ZA, Namiranian K, Klaus J, Kibler K, Dore S: Use of an optimized transient occlusion of the middl cerebral artery protocol for the mouse stroke model. J Stroke Cerebrovasc Dis 2006, 15:133-138.

23. Lee EJ, Chen HY, Wu TS, Chen TY, Ayoub IA, Maynard KI: Acute administration of Ginkgo biloba extract (EGb 761) affords neuroprotection against permanent and transient focal cerebral ischemia in Sprague-Dawley rats. J Neurosci Res 2002, 68:636-645.

24. Ali A, Ahmad FJ, Pillai KK, Vohora D: Evidence of the antiepileptic potential of amiloride with neuropharmacological benefits in rodent models of epilepsy and behavior. Epilepsy Behav 2004, 5:322-328.

25. Lum G, Gambino SR: A comparison of serum Vs heparinised plasma for routine chemistry tests. Am J Clin Pathol 1974, 61:108-113.

26. Caliborne A, Catalase activity: CRC Hand Book of Methods for Oxygen Radical Research.Edited by: Wakd G. Boca Raton, FL: CRC Press; 1985:283-294.

27. Svoboda P, Mosinger B: Catecholamines and the brain microsomal Na,Kadenosinetriphosphatase-I. Protection against lipoperoxida-tive damage. Biochem Pharmacol 1981, 30:427-432.

28. Jollow DJ, Mitchell JR, Zampagline N, Gillette JR: Bromobenzene induced liver necrosis: Protective role of glutathione and evidence for 3,4bromobenzene as the hepatic metabolite. Pharmacology 1974, 11:151-169.

29. Wheeler CR, Salzman JA, Elsayed NM, Omaye ST, Korte DW Jr: Automated assays for superoxide dismutase, catalase, glutathione peroxidase and glutathione reductase activity. Anal Biochem 1990, 184:193-199.

30. Carlberg I, Mannerviek B: Glutathione reductase levels in rat brain. J Biol Chem 1975, 250:5475-5480

31. Habig WH, Pabst MJ, Jakoby WB, Glutathione S-transferases: The first enzymatic step in mercapturic acid formation. J Biol Chem 1974 249:7130-7139.

32. Traystman RJ, Kirsch JR, Koehler RC: Oxygen radical mechanisms of brain injury following ischemia and reperfusion. J Appl Physiol 1991, 71:1185-1195

33. Coyle JT, Puttfarcken PO: Oxidative stress, glutamate and neurodegenerative disorders. Science 1993, 262:689-695.

34. Bains JS, Shaw CA: Neurodegenerative disorders in humans: The role of glutathione in oxidative stress-mediated neuronal death. Brain Res Rev 1997, 25:335-338.

35. Shivakumar BR, Kolluri SV, Ravindranath V: Glutathione and protein thiol homeostasis in brain during reperfusion after cerebral ischemia. $J$ Pharmacol Exp Ther 1995, 274:1167-1173.

36. Love S: Oxidative stress in brain ischemia. Brain Pathol 1999, 9:119-131.

doi:10.1186/1744-9081-6-61

Cite this article as: Liu et al.: Protective effect of extract of Cordyceps sinensis in middle cerebral artery occlusion-induced focal cerebral ischemia in rats. Behavioral and Brain Functions 2010 6:61.

\section{Submit your next manuscript to BioMed Central and take full advantage of:}

- Convenient online submission

- Thorough peer review

- No space constraints or color figure charges

- Immediate publication on acceptance

- Inclusion in PubMed, CAS, Scopus and Google Scholar

- Research which is freely available for redistribution 